\title{
Revealing the microstructural brain damage in amyotrophic lateral sclerosis: the relentless pursuit to approach an imaging biomarker
}

\author{
Revelando o dano cerebral microestrutural na esclerose lateral amiotrófica: a busca \\ incansável por um biomarcador em imagem
}

Antônio José da Rocha ${ }^{1}$, Marco Antonio Chieia ${ }^{2}$

' Santa Casa de Misericórdia de São Paulo, Serviço de Diagnóstico por Imagem, São Paulo SP, Brasil;

${ }^{2}$ Universidade Federal de São Paulo, Departamento de Neurologia e Neurocirurgia, São Paulo SP, Brasil.

\section{Correspondence:}

Antônio José da Rocha; Santa Casa de Misericórdia de São Paulo / Serviço de Diagnóstico por Imagem; Rua Dr. Cesário Motta Junior, 112; 01221-020 São Paulo SP, Brasil; E-mail:antonio.rocha@santacasasp. org.br

Conflict of interest: There is no conflict of interest to declare.

Received 17 April 2017

Accepted 24 April 2017

\section{(cc) BY}

A myotrophic lateral sclerosis (ALS) is the commonest clinical form of the wider neurodegenerative syndrome encompassed by the term motor neuron disease (MND). ALS has a consistent incidence of 1-2/100,000/year, and a lifetime risk estimated at 1 in 400. The disease is characterized by the progressive death of upper motor neurons (UMNs) of the cerebral primary motor cortex and corticospinal tract, in combination with degeneration of lower motor neurons (LMNs) whose origins lie in the brainstem and spinal anterior horns. Loss of motor neurons in general results in weakness, but specifically loss of LMNs results in secondary wasting of the downstream musculature and spasticity arises from loss of UMNs ${ }^{1}$.

About $10 \%$ of cases are considered as being familial (fALS), whereas the remaining $90 \%$ seem to occur sporadically (sALS) with no family history of ALS. Since the first discovery of SOD1 mutations being causative for ALS in $1993^{2}$, researchers all over the world have made great effort to further delineate the genetic basis underlying ALS. Today, more than 30 confirmed major disease genes are listed by the Amyotrophic Lateral Sclerosis Online genetics Database (ALSoD), the most frequently affected being C9orf72 (40\% fALS, 5-6\% sALS; pathogenic repeat expansion in the non-coding region between exons $1 \mathrm{a}$ and $1 \mathrm{~b}$, detection by repeat analysis), SOD1 (20\% fALS, 3\% sALS), FUS ( $5 \%$ fALS, <1\% sALS) and TARDBP (3\% fALS, $2 \%$ sALS) ${ }^{3}$.

In addition to this clinically heterogeneous syndrome a pathologically overlapping with frontotemporal dementia motor signs have been detected by neuropsychological tests in about $50 \%$ of sALS patients. Furthermore typical frontotemporal dementia (FTD) occurs in approximately $10 \%$ of the patients ${ }^{4}$, and the term frontotemporal dementia-motor neuron disease (FTD-MND) continuum was proposed to describe this association ${ }^{4}$, which occurs mostly in C9ORF72-linked fALS 5 .

Despite all this clinical and etiopathogenic complexity, some faces of ALS, including FTD-MND continnum, have been elucidated by magnetic resonance imaging (MRI) techniques, which have proved to be useful to reveal microstructural brain abnormalities associated with different rates of symptom progression ${ }^{6.7}$. A plausible biomarker for upper motor neuron degeneration in ALS is becoming tangible after recent advances in high-throughput MRI techniques, through which one can believe that we are going to the forefront of a breakthrough able to translate research findings into reliable clinical tests that will support the practice of personalized medicine ${ }^{8,910}$.

Advances in neuroimaging have enabled mapping of some endpoints in functional, structural, and molecular aspects of ALS pathology. Menke et al. ${ }^{8}$ have recently reported imaging abnormalities even before clinical symptoms, offering the potential for neuroprotective intervention, particularly in familial cases. Current literature points to DTI technique as the most promising candidate for imaging biomarker in ALS, able to elucidate the brain phenotype of ALS and also detect white matter tract changes in extramotor regions ${ }^{8,10}$.

The results of Chaves et al. ${ }^{11}$ using a 1.5 Tesla MR equipment reinforce the clinical use of fractional anisotropy (FA) to detect extra-motor brain abnormalities in ALS patients. Despite this further multicenter validation with larger cohorts of patients remains mandatory prior to the integration of this technique into the clinical routine as biomarker able to contribute in standard clinical decision-making algorithms. 
1. Ravits JM, La Spada AR. ALS motor phenotype heterogeneity, focality, and spread: deconstructing motor neuron degeneration. Neurology 2009;73:805-11.

2. Rosen DR, Siddique T, Patterson D, et al. Mutations in Cu/Zn superoxide dismutase gene are associated with familial amyotrophic lateral sclerosis. Nature 1993;362:59-62.

3. Su XW, Broach JR, Connor JR, Gerhard GS, Simmons Z. Genetic heterogeneity of amyotrophic lateral sclerosis: implications for clinical practice and research. Muscle \& nerve 2014;49:786-803.

4. Burrell JR, Halliday GM, Kril JJ, et al. The frontotemporal dementia-motor neuron disease continuum. Lancet 2016;388:919-31.

5. Byrne S, Elamin M, Bede P, et al. Cognitive and clinical characteristics of patients with amyotrophic lateral sclerosis carrying a C9orf72 repeat expansion: a population-based cohort study. The Lancet Neurology 2012;11:232-40.

6. van der Graaff MM, Sage CA, Caan MW, et al. Upper and extra-motoneuron involvement in early motoneuron disease: a diffusion tensor imaging study. Brain: a journal of neurology 2011;134:1211-28.
7. Muller HP, Turner MR, Grosskreutz J, et al. A large-scale multicentre cerebral diffusion tensor imaging study in amyotrophic lateral sclerosis. Journal of neurology, neurosurgery, and psychiatry 2016;87:570-9.

8. Menke RA, Agosta F, Grosskreutz J, Filippi M, Turner MR. Neuroimaging Endpoints in Amyotrophic Lateral Sclerosis. Neurotherapeutics: the journal of the American Society for Experimental NeuroTherapeutics 2017;14:11-23.

9. Rocha AJ, Maia Junior AC. Is magnetic resonance imaging a plausible biomarker for upper motor neuron degeneration in amyotrophic lateral sclerosis/primary lateral sclerosis or merely a useful paraclinical tool to exclude mimic syndromes? A critical review of imaging applicability in clinical routine. Arquivos de neuro-psiquiatria 2012;70:532-9.

10. Verstraete E, Foerster BR. Neuroimaging as a New Diagnostic Modality in Amyotrophic Lateral Sclerosis. Neurotherapeutics: the journal of the American Society for Experimental NeuroTherapeutics 2015;12:403-16.

11. Chaves M, Bettini M, Fernandez MC, Basalo MJG, Rojas JI, Besada C, Cristiano E, Golimstok A, Rugiero M. Usefulness of diffusion tensor imaging in amyotrophic lateral sclerosis: potential biomarker and association with the cognitive profile. Arq Neuropsiquiatr 2017;75(5):273-77. https://doi.org/10.1590/0004-282X20170032 